\title{
IMPLEMENTASI PERAMALAN PENJUALAN IKAN LAUT UNTUK OPTIMASI PERSEDIAAN BAHAN BAKU (Studi Kasus di UD Harum Bungah Gresik)
}

\author{
Khanifatus Sa'diyah ${ }^{1}$ dan Narto $^{2 *}$ \\ ${ }^{1,2}$ Program Studi Teknik Industri, Fakultas Teknik, Universitas Qomaruddin \\ Jalan Raya Bungah No.01 Bungah Gresik \\ *email: nartonazriel@gmail.com
}

\begin{abstract}
Indonesian marine waters have high marine resource resources. One of Indonesia's seafood commodities is fish. With proper management and utilization, marine products become one of the promising business opportunities for the community, so that fisheries become one of the supporting sectors of national economic development. UD Harum is one of the businesses engaged in the fisheries sector as a supplier of marine fish raw material needs to meet the needs of the manufacturing industry. To optimize production planning to meet industry demand, forecasting of sea fish sales data forecasting in the previous period is needed to anticipate a shortage of raw materials. The purpose of this forecasting is to implement forecasting using the Single Moving Average (SMA), Weighted Moving Average (WMA) and Centered Moving Average (CMA) methods in forecasting sea fish sales at UD Harum and to find out the best forecasting results to increase sea fish sales at UD Harum. Forecasting results show forecasting using the Single Moving Average (3-monthly) and (5-monthly) methods respectively $8107.67 \mathrm{~kg}$ and $8399.4 \mathrm{~kg}$. For the Weighted Moving Average (3-monthly) and (5-monthly) methods, the results of forecasting are 7268,963 $\mathrm{kg}$ and 7443,452, respectively. As for the Centered Moving Average (3-monthly) method with forecast results of $8107.67 \mathrm{~kg}$. The forecasting method chosen to optimize sales is the Centered Moving Average method with a forecast value of $8107.67 \mathrm{~kg}$ and has the smallest forecasting error compared to other forecasting methods with a MAPE value of 0.30875 and MPE of -0.1720 .
\end{abstract}

Keywords: Forecasting, Sales, Single Moving Average

\section{Pendahuluan}

Sebagian besar luas wilayah indonesia adalah gugusan laut yang luas (Poerwandi 2017). Sumber daya hayati banyak terdapat pada Perairan laut. Salah satu komoditi hasil laut indonesia yang berpotensi tinggi adalah ikan yang dapat menciptakan penghasilan ekonomi (Lowing 2020). Dengan pengelolaan dan pemanfaatan secara tepat, maka hasil laut menjadi salah satu peluang usaha yang menjanjikan bagi masyarakat. Hal tersebut menjadikan sektor perikanan menjadi salah satu sektor pendukung pembagunan ekonomi nasional.

UD Harum merupakan industri yang bergerak di sektor perikanan berupa pemasok kebutuhan bahan baku ikan laut (supplier) ke beberapa industri manufaktur pengolahan ikan laut dan air tawar. Dengan seiring bertambahnya permintaan tersebut maka UD Harum harus melakukan perencanaan produksi guna memenuhi permintaan pabrik dengan melakukan peramalan dari data penjualan ikan laut pada periode sebelumnya.

Tujuan dalam penelitian ini adalah pemanfaatan peramalan dalam memberikan informasi penjualan ikan laut pada UD Harum dan memprediksi tingkat penjualan kurun waktu mendatang. Hasil peramalan digunakan untuk menentukan dan mengantisipasi kurangnya stok ikan laut serta mengoptimasi persediaan bahan baku.

Peramalan merupakan suatu proses perkiraan yang dilakukan dengan sistematis terhadap data aktual masa lalu untuk memperkirakan kebutuhan dimasa mendatang, dan digunakan untuk masa akan datang dengan tingkat penyimpangan sekecil mungkin (Mulyono 1999). Sebelum melakukan peramalan dibutuhkan informasi tentang apa yang diramal dan tujuannya disesuaikan dengan pola data dan metode yang digunakan (Ariyanto, Puspitasari, and Ericawati 2017). Peramalan sangat dibutuhkan dalam pengambilan keputusan 
perusahaan untuk menentukan perencanaan kebutuhan bahan baku sebagai input perusahaan (Hernadewita et al. 2020). Peramalan penjualan adalah perkiraan permintaan kebutuhan akan jumlah barang atau jasa yang diminta oleh industri barang atau jasa pada periode waktu dan wilayah pemasaran tertentu (Berutu, Sediyono, and Sasongko 2013).

Peramalan dengan metode Moving Average menggunakan data masa lalu yang dikumpulkan untuk meramalkan kebutuhan barang atau jasa untuk periode mendatang dengan pola horizontal yang relatif stabil (Hartini, 2011). Sedangkan peramalan dengan metode time series ini antara lain metode Single Moving Average (SMA), Weighted Moving Average (WMA) dan Centered Moving Average (CMA). Diharapkan metode peramalan tersebut bisa menjadi alternatif bagi perusahaan supplier ikan khususnya UD. Harum dalam mengoptimalkan persediaan bahan baku untuk meningkatkan penjualan ikan laut.

\section{Landasan Teori}

\subsection{Penjualan}

Penjualan adalah recana strategis yang dikembangkan untuk memberikan kepuasan dan memenuhi kebutuhan pelanggan guna mendapatkan keuntungan (Marwan 1991). Penjualan merupakan faktor penentu dalam kegiatan suatu perusahaan untuk mendapatkan laba dengan berorientasi untuk memenuhi kebutuhan serta keinginan pelanggan, dengan harapan perusahaan bisa menghasilkan produk (Hidayati 2016). Untuk mendapatkan target usaha diperlukan strategi penjualan melalui kegiatan ekonomis yang menghasilkan keuntungan perusahaan (Wijayanti 2018).

\subsection{Peramalan}

Peramalan merupakan kegiatan memprediksi sesuatu kebutuhan untuk masa mendatang, hal ini bertujuan untuk memberikan gambaran apa dan bagaimana prediksi akan sesuatu itu terjadi. Hal ini memerlukan data masa lalu sebagai bahan dalam melakukan perhitungan atau perkiraan sehingga dapat direncanakan sesuai dengan harapan (Syarif 2010). Setiap tahapan dalam proses peramalan harus diikuti untuk menghasilkan peramalan yang dapat dipertanggungjawabkan sehingga hasilnya efektif dan mendekati harapan (Gaspersz 2005).

\subsection{Pola Data Peramalan Time Series}

Terdapat 4 macam pola data dalam peramalan (Makridakis et al. 1999), (1) Pola Trend, pola data cenderung bergerak naik atau turun dalam periode waktu tertentu. (2) Seasonality (musiman), pola data yang bergantung pada kondisi eksternal seperti cuaca atau kondisi sosial masyarakat. (3) Cycles (Siklus), pola data dipengaruhi oleh fluktuasi ekonomi jangka panjang. (4) Horizontal / Stasionary / Random Variation, Pola data berfluktuasi bergerak bebas tanpa membentuk pola yang jelas.

\subsection{Metode - Metode Deret Waktu}

Time series merupakan model peramalan menggunakan data masa lalu sesuai dengan besarnya permintaan, yang hasilnya membentuk suatu siklus yang digunakan sebagai dasar untuk melakukan peramalan. Tiga jenis metode forecast time series, yaitu (Hartini 2011).

\section{Moving Average (MA)}

Metode moving average digunakan dalam peramalan dengan pola data stabil dengan tren horisontal, hasil peramalan merupakan rata-rata dari data masa lalu, empat jenis time series yaitu:

a. Single Moving Average

$\mathrm{F}_{\mathrm{t}+1}=\frac{\left(x_{\mathrm{t}}+x_{t-1}+\ldots+x_{t-N-1}\right)}{N}=\frac{1}{N} \sum_{t=t-N-1}^{t} x_{t}$ (1)

Dimana :

$\mathrm{Xt} \quad=$ Pengamatan $\mathrm{ke}-\mathrm{t}$

$\mathrm{Ft}+1=$ Nilai ramalan $\mathrm{ke}-\mathrm{t}+1$

\section{b. Double Moving Average}

$$
\begin{aligned}
& \mathrm{S}_{\mathrm{t}}^{\prime}=\frac{\sum_{\mathrm{i}=\mathrm{1}}^{\mathrm{t}-N+1} x_{\mathrm{i}}}{N} \\
& \mathrm{~S}_{\mathrm{t}}^{\prime \prime}=\frac{\sum_{\mathrm{i}=1}^{\mathrm{t}-N+1} S_{v_{\mathrm{i}}}}{N} \\
& \alpha_{\mathrm{t}}=\mathrm{S}_{\mathrm{t}}^{\prime}+\left(\mathrm{S}_{\mathrm{t}}^{\prime}-\mathrm{S}_{\mathrm{t}}^{\prime \prime}\right)=2 \mathrm{~S}_{\mathrm{t}}^{\prime}-\mathrm{S}_{\mathrm{t}}^{\prime \prime} \\
& b_{\mathrm{t}}=\frac{2}{N-1}\left(\mathrm{~S}_{\left.\mathrm{t}-\mathrm{S}_{\mathrm{t}}\right)}^{\prime \prime}\right. \\
& \mathrm{F}_{\mathrm{t}+\mathrm{m}}=\alpha_{\mathrm{t}+} b_{\mathrm{t}} \cdot m \\
& \mathrm{Dimana}^{\prime} \quad=\text { Pergerakan pertama } \\
& \mathrm{S}^{\prime \prime} \quad=\text { Pergerakan kedua } \\
& \mathrm{F}_{\mathrm{t}+\mathrm{m}}=\text { m merupakan selisih periode } \mathrm{t} \\
& \text { dengan periode peramalan }
\end{aligned}
$$

c. Weighted Moving Average

$\mathrm{WMA}=\sum_{i=1}^{n} W i D i$

Dimana :

$\mathrm{Wi}=$ Bobot pada nilai ke-i

Di $=$ Demand (kebutuhan) pada nilai ke-i

d. Center Moving Average

Contoh persamaan untuk $\mathrm{F}_{3}$ :

$\mathrm{F}_{\mathrm{t}+1}=\frac{x_{t-2}+x_{t-1}+x_{t}+x_{t+1}+x_{t+2}}{5}$

Keterangan :

$\mathrm{Xt}=$ Data pengamatan pada waktu $\mathrm{ke}-\mathrm{t}$ 
$\mathrm{Ft}+1=$ Nilai ramalan pada waktu $\mathrm{ke}-\mathrm{t}+1$

\section{Exponential Smoothing}

Digunakan pada jenis data Fluktuatif, terdapat empat jenis metode exponential smoothing, yaitu:

a. Single Exponential Smoothing

$$
\mathrm{F}_{\mathrm{t}+1}=\alpha \mathrm{X}_{\mathrm{i}}+(1-\alpha) \mathrm{F}_{\mathrm{t}-1}
$$

Dimana:

$$
\begin{array}{ll}
\alpha & =\text { Konstanta smoothing } \\
\mathrm{Xi} & =\text { Data demand (kebutuhan) } \mathrm{ke}-\mathrm{i}
\end{array}
$$

\section{b. Double Exponential Smoothing}

$$
\begin{aligned}
& \mathrm{S}_{\mathrm{t}}^{\prime}=\alpha \mathrm{D}_{\mathrm{t}}+(1-\alpha) \mathrm{S}_{\mathrm{t}-1}^{\prime} \\
& \mathrm{S}_{\mathrm{t}}^{\prime \prime}=\alpha \mathrm{S}_{\mathrm{t}}^{\prime}+(1-\alpha) \mathrm{S}_{\mathrm{t}-1} \\
& \alpha_{\mathrm{t}}=2 \mathrm{~S}_{\mathrm{t}}^{\prime}-\mathrm{S}_{\mathrm{t}}^{\prime \prime} \\
& b_{\mathrm{t}}=\frac{\alpha\left(\mathrm{S}^{\prime} \mathrm{t}-\mathrm{S}^{\mathrm{m}} \mathrm{t}\right)}{1-\alpha} \\
& \mathrm{Ft}+\mathrm{m} \quad \quad=\alpha_{\mathrm{t}}+b_{\mathrm{t}} \cdot m
\end{aligned}
$$

Dimana :

$S^{\prime}=$ Laju data pertama

$\mathrm{S}^{\prime \prime}=$ Laju data kedua

$\mathrm{F}_{\mathrm{t}+\mathrm{m}}=\mathrm{m}$ merupakan selisih periode $\mathrm{t}$ dengan periode peramalan

\section{c. Single Exponential Smoothing with Trend}

Menggunakan trend hasil estimasi yang Smooth dari pertumbuhan rata-rata pada akhir periode.

\section{d. Double Exponential Smoothing with Trend}

Metode Exponential Smoothing dengan trend naik sehingga dibutuhkan 2 kali proses.

\section{Box-Jenkins (ARIMA)}

Metode ARIMA adalah metode yang menghasilkan peramalan optimal dengan tren data serta situasi peramalan yang sulit. Metode Box-Jenkins merupakan suatu prosedur interatif memilih model terbaik untuk series yang stasioner dari suatu kelompok model time series linier (Mulyono 1999).

\subsection{Pengukuran Kesalahan Peramalan}

Pengukuran akurasi hasil peramalan untuk mengetahui tingkat selisih antara hasil data peramalan dengan permintaan yang sesungguhnya (Nasution 2006).

a. Mean Absolute Deviation

$\mathrm{MAD}=\sum \frac{\left|A_{\mathrm{t}}-F_{\mathrm{t}}\right|}{n}$

Dimana:

$A_{t}=$ Data periode ke $t$
$F_{t}=$ Peramalan periode ke $t$

$n=$ Jumlah periode peramalan

b. Mean Square Error

$$
\mathrm{MSE}=\sum \frac{\left.\mid A_{\mathrm{t}}-F_{\mathrm{t}}\right]^{2}}{n}
$$

Dimana:

$A_{t} \quad=$ Data periode ke $t$

$F_{t} \quad=$ Peramalan periode ke $t$

$n$ = Jumlah periode peramalan

c. Mean Forecast Error

$$
\mathrm{MFE}=\sum \frac{\left(A_{\mathrm{t}}-F_{\mathrm{t}}\right)}{n}
$$

Dimana:

$A_{t} \quad=$ Data periode ke $t$

$F_{t} \quad=$ Peramalan periode ke $t$

$n \quad=$ Jumlah periode peramalan

d. Mean Absolute Percentage Error

$$
\text { MAPE }=\left(\frac{100}{n}\right) \sum\left|A_{t}-\frac{F_{t}}{A_{t}}\right|
$$

Keterangan:

$A_{t} \quad=$ Data periode ke $t$

$F_{t} \quad=$ Peramalan periode ke $t$

$n$ = Jumlah periode peramalan

\section{Metode Penelitian}

Pengumpulan data diperoleh dari data historis penjualan tiap hari ikan laut pada UD Harum pada bulan Februari 2020 - bulan April 2020, data bulan tersebut dipilih karena tingginya tingkat permintaan ikan dari pelanggan. Analisi data menggunakan metode Single Moving Average (SMA), Weighted Moving Average (WMA) dan Centered Moving Average (CMA) dengan pertimbangan trend pola data permintaan ikan serta untuk memperoleh nilai peramalan permintaan produk dimasa yang akan datang, sehingga tingkat persediaan bahan baku ikan dapat disesuaikan dengan tingkat permintaan yang ada. Setelah diperoleh hasil peramalan selanjutnya dilakukan rekapitulasi untuk mengetahui tingkat nilai error untuk menentukan metode terpilih. Kemudian langkah akhir adalah perhitungan tracking signal untuk mengetahui tingkat ketepatan hasil peramalan.

\section{Hasil Dan Pembahasan}

Pada tabel 1 dibawah merupakan data yang diperoleh dari perusahaan tentang penjualan ikan laut selama periode bulan Februari sampai April 
2020. Gambar 1 merupakan data historis penjualan ikan laut pada periode bulan Februari sampai April 2020 yang disajikan dalam grafik. Berdasarkan grafik penjualan ikan laut yang memiliki kecenderungan fluktuatif setiap periode.

Tabel 1. Data Penjualan Ikan Laut UD Harum Bulan Februari 2020 - Bulan April 2020

\begin{tabular}{lcr}
\hline Bulan & Periode & Berat $(\mathbf{K g})$ \\
\hline Februari & 1 & 10.189 \\
& 2 & 15.138 \\
& 3 & 5.666 \\
Maret & 4 & 9.079 \\
& 5 & 12.191 \\
& 6 & 7.731 \\
& 7 & 6.428 \\
April & 8 & 12.171 \\
& 9 & 5.503 \\
& 10 & 11.221 \\
& 11 & 6.162 \\
& 12 & 6.940 \\
\hline
\end{tabular}

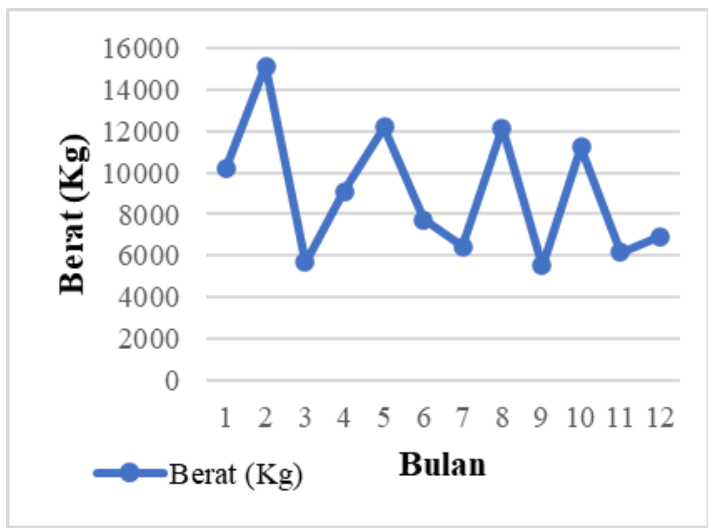

Gambar 1. Pola Historis Data Aktual Penjualan Ikan Laut Pada UD Harum Bulan Februari 2020 Bulan April 2020

Berikut didapatkan hasil perhitungan yang disajikan pada tabel 2. Data yang memiliki pola konstan, metode peramalan Time Series yang digunakan adalah Single Moving Averages (3 bulanan dan 5 bulanan), Weighted Moving Averages ( 3 bulan terbobot dan 5 bulan terbobot), dan Centered Moving Average (3 bulanan). Berikut perhitungan peramalan dengan nilai kesalahan tidak terlalu besar.

Tabel 3. Rekapitulasi Perhitungan Peramalan Penjualan Ikan Laut

\begin{tabular}{rrrrrr}
\hline t & 3-SMA & 5-SMA & 3-WMA & 5-WMA & 3-CMA \\
\hline 1 & & & & & \\
2 & & & & & 10.331 \\
3 & & & $8.967,93$ & & 9.961 \\
4 & $10.331,00$ & & $8.881,08$ & & $8.978,7$ \\
5 & $9.961,00$ & & $9.456,13$ & $9.973,21$ & 9.667 \\
6 & $8.978,67$ & $4.058,40$ & 10.13 & \\
7 & $9.667,00$ & $5.854,13$ & $9.184,91$ & $9.597,83$ & $8.783,3$ \\
8 & $8.783,33$ & $7.787,53$ & $7.545,39$ & $8.386,70$ & $8.776,7$
\end{tabular}

\begin{tabular}{cccccr}
\hline t & 3-SMA & 5-SMA & 3-WMA & 5-WMA & 3-CMA \\
\hline 9 & $8.776,67$ & $9.544,20$ & $9.950,00$ & $9.026,85$ & 8.034 \\
10 & $8.034,00$ & $9.233,33$ & $7.536,04$ & $8.597,67$ & $9.631,7$ \\
11 & $9.631,67$ & $8.847,93$ & $9.702,48$ & $8.635,30$ & $7.628,7$ \\
12 & $7.628,67$ & $8.978,53$ & $7.528,92$ & $8.638,58$ & $8.107,7$ \\
\hline
\end{tabular}

\subsection{Analisis Kesalahan}

Dalam melakukan peramalan terjadi ketidaksesuaian antar data aktual dengan hasil permalan, maka dilakukan hitung error dengan metode analisis kesalahan MSE, MPE, MAPE dan SSE.

Tabel 4. Hasil Perbandingan

\begin{tabular}{rrrrr}
\hline Metode & \multicolumn{1}{c}{ MSE } & MPE & MAPE & \multicolumn{1}{c}{ SSE } \\
\hline 3 SMA & $7.050 .132,62$ & $-0,1461$ & 0,31174 & $19.061 .956,00$ \\
5 SMA & $9.331 .411,63$ & $-0,2406$ & 0,39494 & $59.431 .764,64$ \\
3 WMA & $10.403 .074,98$ & $-0,1396$ & 0,36012 & $5.414 .407,76$ \\
5 WMA & $8.242 .570,81$ & $-0,2178$ & 0,37348 & $44.891 .889,42$ \\
3 CMA & $6.612 .239,45$ & $-0,1720$ & 0,30875 & $46.346 .140,84$ \\
\hline
\end{tabular}

Rekapitulasi dan verifikasi data konstan diatas, diperoleh nilai MAPE terkecil adalah metode Centered Moving Average (CMA) sebesar 0,30875. Maka metode Centered Moving Average (CMA) adalah metode terbaik untuk melakukan peramalan penjualan ikan laut pada UD Harum. Setelah melakukan verifikasi data maka dilakukan validasi data menggunakan uji peta kendali tracking signal.

\subsection{Tracking Signal}

Hasil peramalan dengan metode Centered Moving Average (CMA) ketepatan pengukurannya dapat menggunakan Tracking Signal (TS). Perhitungan tracking signal dapat dilihat pada tabel 5 untuk metode Centered Moving Average (CMA).

Tabel 5. Perhitungan Tracking Signal Metode CMA (Bobot $=3)$

\begin{tabular}{cc}
\hline Periode & Tracking Signal \\
\hline 1 & 1 \\
2 & 0,1125027 \\
3 & 0,1996233 \\
4 & 1,0698428 \\
5 & 0,8154215 \\
6 & $-0,104976$ \\
7 & 1,4070735 \\
8 & $-0,087662$ \\
9 & 1,1126044 \\
10 & 0,4805687 \\
11 & 0,0813767 \\
12 &
\end{tabular}

Perhitungan hasil tracking signal metode Centered Moving Average (CMA) ditampilkan juga dalam bentuk grafik. Perhitungan yang telah dilakukan tersebut, hasil dalam bentuk grafik dimana grafik ini akan menunjukkan keakuratan sebuah peramalan penjualan ikan laut. Grafik tracking signal dari metode Centered Moving Average (CMA) dengan bobot $=3$ dapat dilihat 
pada gambar 2. Pada gambar dibawah, data tracking signal pada metode Centered Moving Average (CMA) tidak keluar batas kontrol atas dan batas kontrol bawah, sehingga data valid.

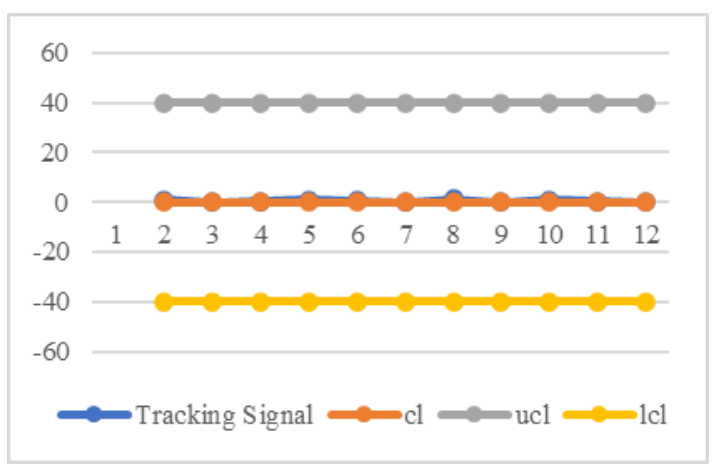

Gambar 2. Grafik Tracking Signal

\section{Kesimpulan}

Metode terbaik yang dapat digunakan untuk peramalan penjualan untuk mengoptimasi kebutuhan bahan baku ikan laut adalah metode Centered Moving Average (CMA), dengan dengan hasil permalan pada periode $\mathrm{t}$ ke-12 sebesar 8.107,7, artinya jumlah persediaan yang aman adalah sebesar $8.108 \mathrm{~kg}$ ikan laut. Apabila stock persediaan tersebut dipenuhi maka jumlah permintaan ikan laut dapat terpenuhi dengan baik. Selain itu metode Centered Moving Average (CMA) nilai (error) peramalan terkecil dibandingkan dengan metode yang lain, nilai MPE sebesar $-0,1720$ dan MAPE sebesar 0,30875. Sehingga metode Centered Moving Average (CMA) cocok digunakan oleh UD. Harum dalam melakukan peramalan penjualan ikan laut pada periode berikutnya.

\section{Daftar Referensi}

Ariyanto, Rudy, Dwi Puspitasari, and Fifi Ericawati. 2017. "Penerapan Metode Double Exponential Smoothing Pada Peramalan Produksi Tanaman Pangan." Informatika Polinema 4(1):57-62.

Berutu, Sunneng Sandino, Eko Sediyono, and Priyo Sidik Sasongko. 2013. "Peramalan Penjualan Dengan Metode Fuzzy Time Series Ruey Chin Tsaur." HimsyaTech 11(1):1-11.

Gaspersz, Vincent. 2005. Total Quality Management. Jakarta: Gramedia Pustaka Utama.

Hartini, Sri. 2011. Teknik Mencapai Produksi Optimal. Ketiga. Bandung: CV Lubuk Agung.

Hernadewita, Yan Kurnia Hadi, Muhammad Julian Syaputra, and Donny Setiawan.
2020. "Peramalan Penjualan Obat Generik Melalui Time Series Forecasting Model Pada Perusahaan Farmasi Di Tangerang: Studi Kasus." JOURNAL INDUSTRIAL ENGINEERING \& MANAGEMENT RESEARCH ( JIEMAR) 1(2):35-49.

Hidayati, R. .. 2016. "Pengaruh Teknologi Informasi, Kinerja Individual Dan Volume Penjualan Terhadap Peningkatan Laba Pada Usaha Makanan Kecil Menengah Di Yogyakarta." Universitas Islam Indonesia.

Lowing, Tivani. 2020. “Analisis Manajemen Rantai Pasok Ikan Cakalang Di Tempat Pelelangan Ikan Tumumpa Kota Manado.” Jurnal EMBA 8(1):575-85.

Makridakis, S., C. Steven, V. E. Wheelwright, and McGee. 1999. Metode Dan Aplikasi Peramalan Jilid 2. Jakarta: Binarupa Aksara.

Marwan. 1991. Marketing. Yogyakarta: UPPAMP YKPN.

Mulyono, S. 1999. Peramalan Bisnis Dan Ekonometrika. Yogyakarta: BPFE.

Nasution, Arman Hakim. 2006. Manajemen Industri. Yogyakarta: Andi Offset.

Poerwandi, B. S. ST. 2017. "BMKT Adalah Milik Bangsa Dan Identitas Kita Sebagai Negara Maritim." Direktorat Jendral Pengelolaan Ruang Laut.

Syarif, Nanda Muhammad. 2010. “Analisis Peramalan Penjualan Produk Brand Dadung Pada PT. Mondrian Klaten." Universitas Sebelas Maret.

Wijayanti, Ratna. 2018. "Pengendalian Persediaan Bahan Baku Dan Peramalan Penjualan Produk Terhadap Pencapaian Laba Perusahaan.” Pp. 134-47 in Prosiding Seminar Nasional Lembaga Penelitian dan Pengabdian Kepada Masyarakat Universitas PGRI Semarang. 